\title{
Ionic Dependence of Glutamate Neurotoxicity
}

\author{
Dennis W. Choi \\ Department of Neurology, Stanford University Medical Center, Stanford, California 94305
}

The cellular mechanisms by which excess exposure to the excitatory neurotransmitter glutamate can produce neuronal injury are unknown. More than a decade ago it was hypothesized that glutamate neurotoxicity (GNT) is a direct consequence of excessive neuronal excitation ("excitotoxicity" hypothesis); more recently, it has been hypothesized that a $\mathrm{Ca}$ influx triggered by glutamate exposure might mediate GNT ( $\mathrm{Ca}$ hypothesis). A basic test to discriminate between these hypotheses would be to determine the dependence of GNT on the extracellular ionic environment. The excitotoxicity hypothesis predicts that GNT should depend critically on the presence of extracellular $\mathrm{Na}$, since that ion appears to mediate glutamate neuroexcitation in the CNS; the Ca hypothesis predicts that GNT should depend critically on the presence of extracellular $\mathrm{Ca}$.

The focus of the present experiments was to determine the effects of several alterations in the extracellular ionic environment upon the serial morphologic changes that occur after mouse neocortical neurons in cell culture receive toxic exposure to glutamate. The results suggest that GNT in cortical neurons can be separated into 2 components distinguishable on the basis of differences in time course and ionic dependence. The first component, marked by neuronal swelling, occurs early, is dependent on extracellular $\mathrm{Na}$ and $\mathrm{Cl}$, can be mimicked by high $\mathrm{K}$, and is thus possibly "excitotoxic." The second component, marked by gradual neuronal disintegration, occurs late, is dependent on extracellular $\mathrm{Ca}$, can be mimicked by $\mathrm{A23187}$, and is thus possibly mediated by a transmembrane influx of $\mathrm{Ca}$. While either component alone is ultimately capable of producing irreversible neuronal injury, the Ca-dependent mechanism predominates at lower exposures to glutamate.

Glutamate exposure likely leads to a Ca influx both through glutamate-activated cation channels and through voltagedependent $\mathrm{Ca}$ channels activated by membrane depolarization. Addition of $20 \mathrm{~mm}$ Mg, however, did not substantially block GNT; this finding, together with the observation that GNT is largely preserved in sodium-free solution, supports the notion that the activation of voltage-dependent $\mathrm{Ca}$ channels may not be required for lethal Ca entry. The possibility that $\mathbf{N}$-methyl-D-aspartate receptors may play a dominant role in mediating glutamate-induced lethal $\mathrm{Ca}$ influx is discussed.

\footnotetext{
Received Feb. 25, 1986; revised June 12, 1986; accepted July 23, 1986.

I wish to thank S. Rothman and C. Jahr for helpful discussions, and M. Yokoyama for expert technical assistance. This work was supported by grants BRSG RR 5353 and NS21628 from the National Institute of Health, grants from the Wills and Hereditary Disease Foundations, and a Hartford Fellowship from the John A. Hartford Foundation.

Correspondence should be addressed to Dennis W. Choi at the above address. Copyright (C) 1987 Society for Neuroscience 0270-6474/87/020369-11\$02.00/0
}

The preceding paper describes the use of a mouse cortical cell system to study the phenomenon of glutamate neurotoxicity (GNT), a process that may contribute to the neuronal death seen in a variety of acute and chronic neurological diseases (Coyle et al., 1981). Although GNT was first observed nearly 30 years ago in the mouse retina (Lucas and Newhouse, 1957), and although the structurally related compound kainate has been used for a decade as a convenient method of producing axon-sparing experimental brain lesions (Olney et al., 1974; Coyle, 1983), the mechanisms by which excess exposure to glutamate can lead to neuronal injury remain unknown.

One attractive hypothesis, first proposed by Olney and colleagues (Olney et al., 1971), is that the neurotoxicity of glutamate and related compounds is a direct consequence of the neuroexcitation produced; i.e., that the lasting depolarization produced by continued exposure to glutamate is lethal per se, perhaps because of associated intracellular volume expansion or profound depletion of cell energy reserves. Since glutamate neuroexcitation is in most cases mediated by an inward movement of $\mathrm{Na}$ ions through chemically activated membrane conductances (Barker and Nicoll, 1973; Hablitz and Langmoen, 1982), a basic prediction of this "excitotoxic" model would therefore be that GNT should depend upon the presence of extracellular $\mathrm{Na}$.

More recently, attention has been drawn to the possibility that Ca entry may serve as a common pathway in the injury of a variety of cell types by a variety of toxins. Damage to cultured hepatocytes by membrane-active toxins (Schanne et al., 1979), to skeletal muscle by sustained action of cholinergic agonists (Leonard and Salpeter, 1979), and to locust muscle by sustained action of glutamate (Duce et al., 1983), all appear to be attenuated by a reduction in the concentration of extracellular $\mathrm{Ca}$. In addition, heavy accumulations of $\mathrm{Ca}$ persist selectively in vulnerable neurons of the hippocampus following ischemic insult (Simon et al., 1984a). It has therefore been proposed that the toxic effects of glutamate on central neurons may be similarly mediated by an influx of extracellular Ca (Berdichevsky et al., 1983; Coyle, 1983).

A logical first step, therefore, in elucidating the cellular mechanism of GNT would be to define the dependence of GNT on the extracellular ionic environment, particularly with respect to extracellular $\mathrm{Na}$ and $\mathrm{Ca}$ ions. Such a study is difficult in vivo, but manageable in vitro. In an initial series of experiments reported previously (Choi, 1985), GNT in cortical cell culture was found to depend much more heavily on the presence of extracellular $\mathrm{Ca}$ than on the presence of extracellular Na. However, other in vitro studies have recently been reported in which GNT was demonstrated in the absence of extracellular Ca (Price et al., 1985; Rothman, 1985), and a critical role for $\mathrm{Cl}$ ions has been suggested by these authors. The purpose of this study was 

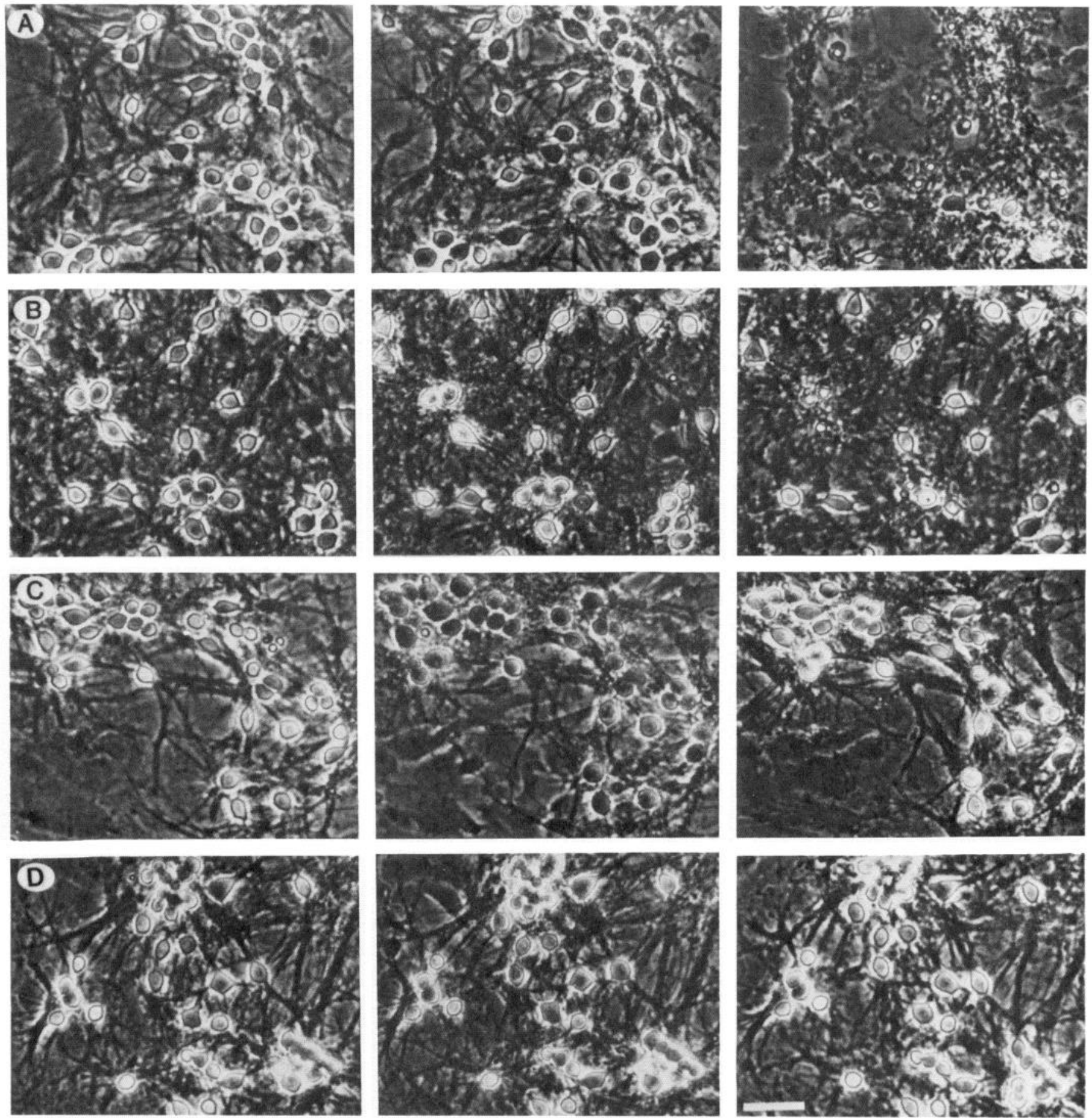

Figure 1. Effect of removing Na and/or Ca on GNT. Phase-contrast photomicrographs of an identified field of cortical neurons before (left column), immediately after (middle column), and $1 \mathrm{~d}$ after (right column) brief pulse exposure to glutamate $(0.5 \mathrm{~mm}$ for $5 \mathrm{~min})$. Each row $(A-D)$ shows the results of exposure under different ionic conditions: $A$, control salt solution (CSS); $B$, Na replaced by choline (Na-free solution); $C$, Ca removed (Ca-free solution); and $D$, both $\mathrm{Na}$ replaced by choline and $\mathrm{Ca}$ removed $(\mathrm{Na} / \mathrm{Ca}$-free solution). All 4 exposures were carried out concurrently on sister cultures from a single plating. The bar in $D$, right, corresponds to $50 \mu \mathrm{m}$ and applies to all parts.

to examine further the ionic dependence of GNT in an effort to reconcile these observations.

\section{Materials and Methods}

Methods. The preparation of cortical cell cultures, intracellular recording, bath exposure to glutamate, and quantitation of neuronal cell survival have been described in the preceding paper. Only mature (14-24 $\mathrm{d}$ in vitro) cortical cultures were selected for study; whenever possible, comparisons were made on matched sister cultures derived from a single plating. Because of the suggestion (see below) that extracellular $\mathrm{Na}$ and $\mathrm{Ca}$ ions were important for GNT, the washout of glutamate was in all experiments initiated with $\mathrm{Ca} / \mathrm{Na}$-free solution, thereby reducing the glutamate concentration by a factor of 36 before any reintroduction of $\mathrm{Ca}$ or $\mathrm{Na}$ ions in the washout procedure.

Solutions and drugs. The composition of solutions used during exposure of cortical neurons to glutamate is detailed in Table 1. The standard "control salt solution" (CSS) is the same as used in previous 
The Journal of Neuroscience, February 1987, 7(2) 371
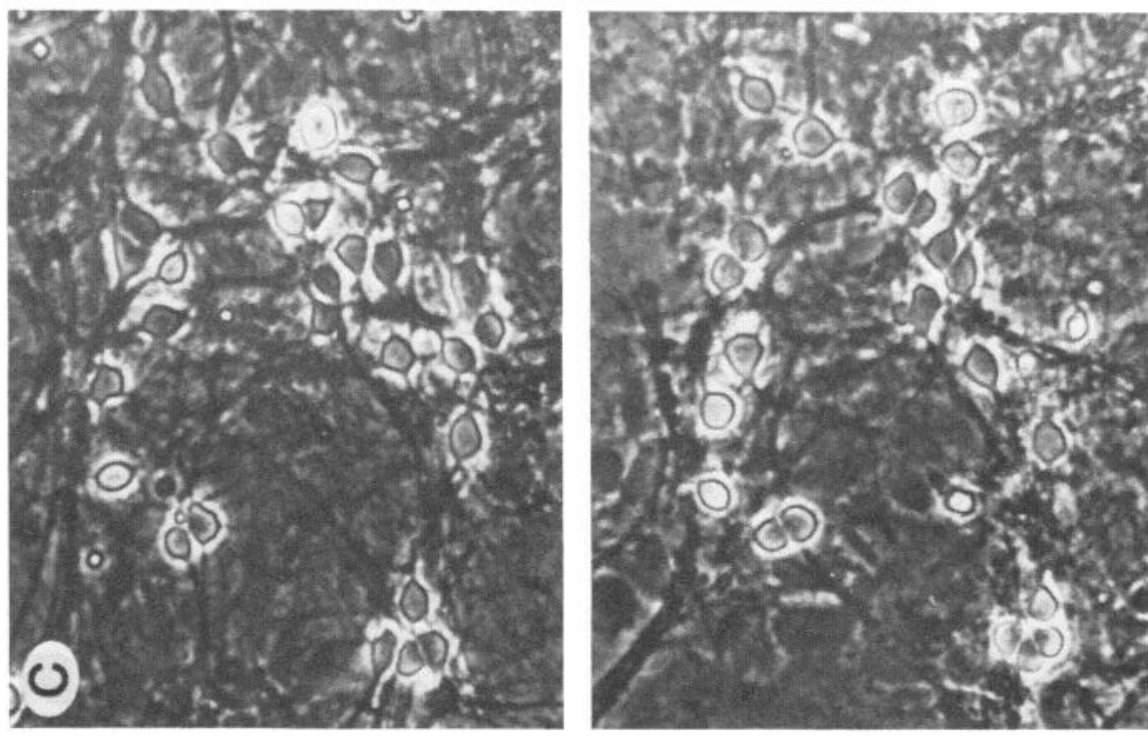

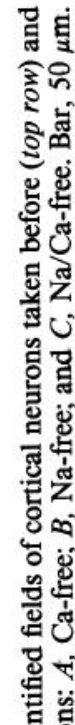
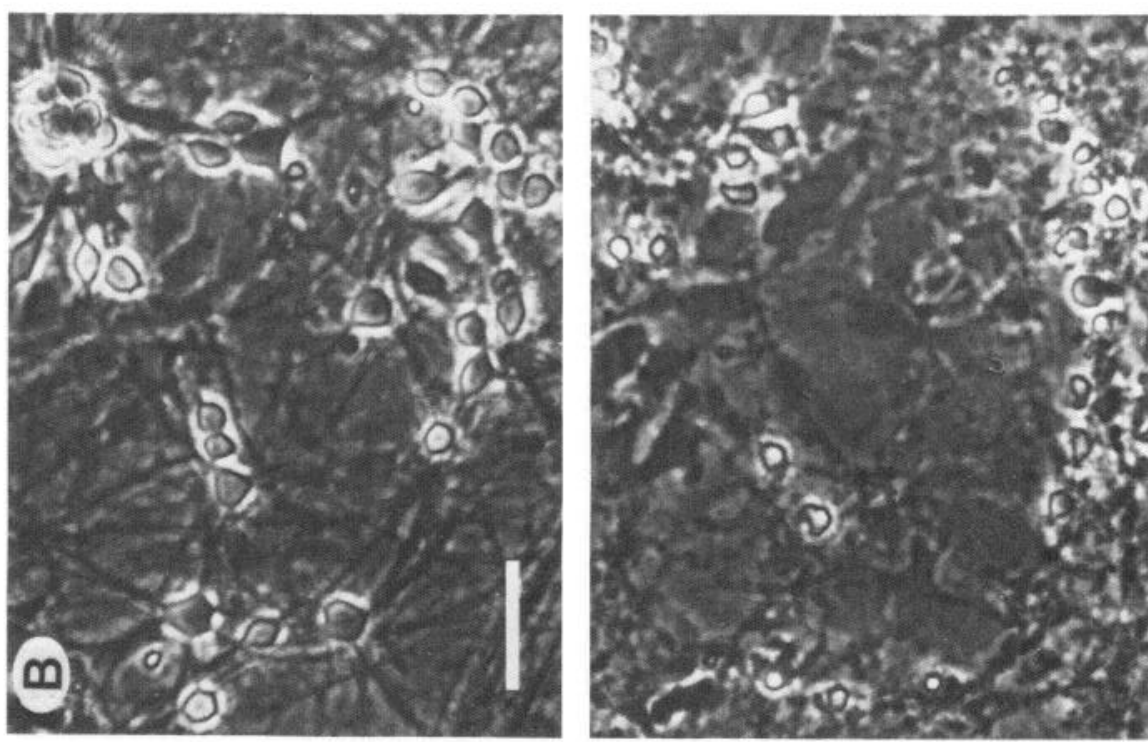

응

s.

过

을

통

는

票

을

ชํ.

:

․ㅡㄹ

응.

징

范

范
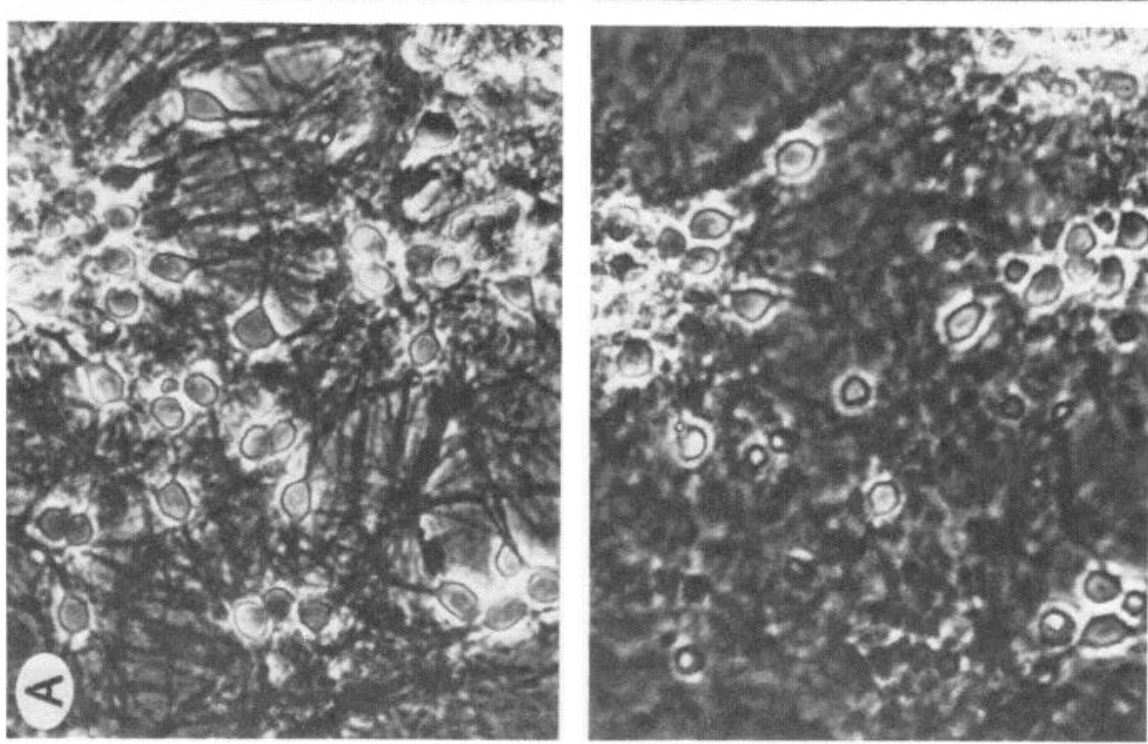

कo ब

远

总

홍

起

of क्ष

를

in

สㅇ

乙一

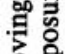

ริํํㄹ

ํํำ

倦

?

ริษ

这尔 


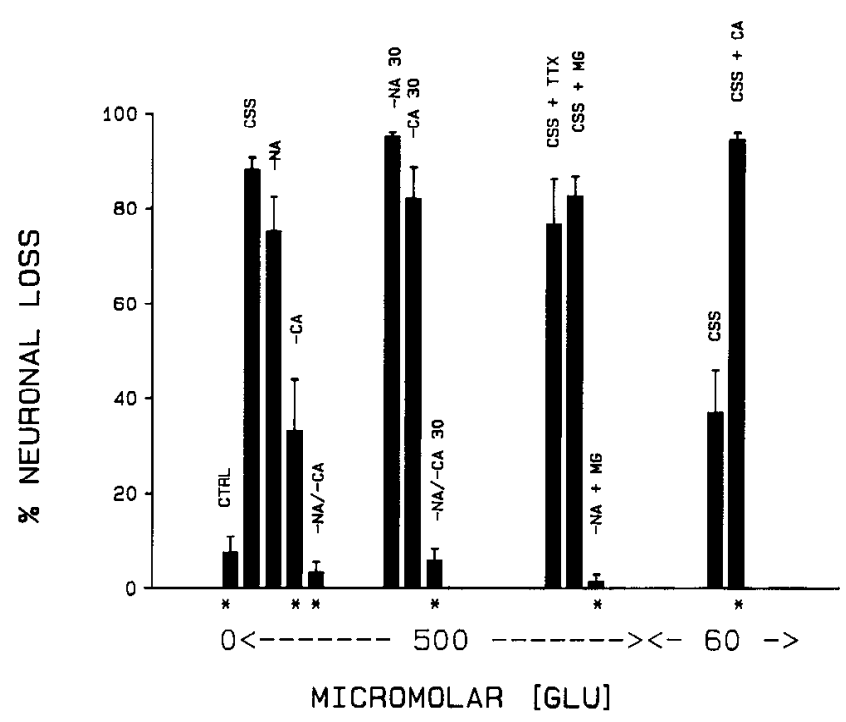

Figure 3. Quantitative comparison of glutamate-induced cell loss in various experimental solutions. Vertical bars depict mean and SEM of cortical neuronal cell loss/injury, expressed as a percentage of the original cell count, observed with glutamate exposure under the specified conditions. Bars at far left, The baseline procedural damage observed without glutamate (CTRL, $n=6$ ) is compared to the damage produced by exposure to $0.5 \mathrm{~mm}$ glutamate in CSS $(n=14)$, Na-free solution [(-) Na; $n=6$ ], Ca-free solution [(-)Ca;n=6], and $\mathrm{Na} / \mathrm{Ca}$-free solution [(-) Na/ $(-) \mathrm{Ca} ; n=5]$. Bars at near left, Results obtaincd when the exposure to $0.5 \mathrm{~mm}$ glutamate was extended to $30 \mathrm{~min}$ in $(-) \mathrm{Na}(n=$ $4),(-) \mathrm{Ca}(n=6)$, and $(-) \mathrm{Na} /(-) \mathrm{Ca}(n=4)$ solutions. Bars at near right, Results obtained with $0.5 \mathrm{~mm}$ glutamate for $5 \mathrm{~min}$ again, in CSS + $1 \mu \mathrm{M}$ TTX $(n=5), \mathrm{CSS}+20 \mathrm{mM} \mathrm{MgCl}_{2}(n=5)$, and (-) Na $+20 \mathrm{~mm}$ $\mathrm{MgCl}_{2}(n=3)$ solutions. Bars at far right, Results obtained with 5 min exposure to a reduced glutamate concentration $(60 \mu \mathrm{M})$ in CSS $(n=6)$ and $\mathrm{CSS}+5 \mathrm{mM} \mathrm{CaCl}_{2}(n=3)$. The asterisk below some of the bars indicates a statistically significant difference compared with the same exposure to glutamate in CSS ( $p<0.05,2$-tailed $t$ test).

experiments. The calcium ionophore A23187 (Calbiochem) was dissolved in dimethyl sulfoxide (DMSO; $10 \mathrm{~mm}$ stock solution) prior to final dilution.

In control experiments, appropriate exposure to any of the salt solutions alone (in the absence of added glutamate) was well toleratcd by cortical neurons.

\section{Results}

\section{$\mathrm{Na}$ and $\mathrm{Ca}$ dependence of $\mathrm{GNT}$}

The previously reported experiments examining the effects of reduced extracellular $\mathrm{Na}$ or $\mathrm{Ca}$ concentrations on GNT (Choi, 1985) were extended to include systematic observation of both immediate and late sequelae of glutamate exposure. As reported in the previous paper, exposure of cortical neurons to $0.5 \mathrm{~mm}$ glutamate in CSS was followed within minutes by acute swelling, darkening, and increased granularity of the cell body; by the following morning, most neurons had disintegrated into debris (Fig. 1A).

If the same procedure was carried out in the absence of extracellular $\mathrm{Na}$, with choline used in place of $\mathrm{Na}$, the acute morphological changes were absent, but late cell death was reduced only by a variable, generally small, amount (Fig. $1 B$; see also the greater cell loss in Fig. $8 C$; $>20$ experiments). If on the other hand, the procedure was carried out in the absence of $\mathrm{Ca}$, the acute neuronal swelling was actually intensified, but late cell death was always markedly reduced (Fig. $1 C ;>30$ experiments). In the absence of both $\mathrm{Na}$ and $\mathrm{Ca}$, with choline in place of $\mathrm{Na}$,

\begin{tabular}{|c|c|c|c|c|c|c|}
\hline \multirow[b]{2}{*}{ Additive } & \multicolumn{6}{|c|}{ Solution (mM) } \\
\hline & CSS & $\begin{array}{l}\mathrm{Na} \\
\text { free }\end{array}$ & $\begin{array}{l}\mathrm{Ca} \\
\text { free }\end{array}$ & $\begin{array}{l}\mathrm{Na} / \mathrm{Ca} \\
\text { free }\end{array}$ & $\begin{array}{l}\mathrm{Cl} \\
\text { free }\end{array}$ & $100 \mathrm{~K}$ \\
\hline $\mathrm{NaCl}$ & 120 & & 120 & & & 25 \\
\hline $\mathrm{KCl}$ & 5.4 & 5.4 & 5.4 & 5.4 & & 100 \\
\hline $\mathrm{MgCl}_{2}$ & 0.8 & 0.8 & 0.8 & 0.8 & & 0.8 \\
\hline $\mathrm{CaCl}_{2}$ & 1.8 & 1.8 & & & & 1.8 \\
\hline Tris- $\mathrm{Cl}(\mathrm{pH} 7.4)$ & 25 & 25 & 25 & 25 & & 25 \\
\hline $\mathrm{NaHCO}_{3}$ & & & & & 4.2 & \\
\hline Glucose & 15 & 15 & 15 & 15 & 15 & 15 \\
\hline Choline- $\mathrm{Cl}$ & & 120 & & 120 & & \\
\hline $\mathrm{K}_{2} \mathrm{SO}_{4}$ & & & & & 2.7 & \\
\hline $\mathrm{MgSO}_{4}$ & & & & & 0.8 & \\
\hline $\mathrm{Ca}$ gluconate & & & & & 1.8 & \\
\hline $\mathrm{Na}$ isothionate & & & & & 120 & \\
\hline Sucrose $^{a}$ & & & & & 35 & \\
\hline
\end{tabular}

${ }^{a}$ Sucrose was added to the chloride-free solution to maintain osmolarity.

both the acute swelling and the late cell death were invariably prevented (Fig. $1 D ;>15$ experiments).

Neither the large protective effect of removing $\mathrm{Ca}$ nor the small protective effect of choline substitution on GNT was absolute. Increasing the duration of glutamate exposure to $30 \mathrm{~min}$ produced substantial cell death in both Na-free (Fig. $2 A$ ) and Ca-free (Fig. 2B) conditions. However, in the absence of both $\mathrm{Na}$ and $\mathrm{Ca}$, little neuronal death was seen even after such prolonged glutamate exposures (Fig. 2C). Quantitative cell counts of identified cortical neurons before and after glutamate exposure in these (and other-see below) solutions are presented in Figure 3.

These observations suggested that GNT might result from the sum of 2 components: one acute and $\mathrm{Na}$ dependent, and the other late and $\mathrm{Ca}$ dependent. Each component was then examined in more detail in the following experiments.

\section{The acute component of GNT}

Serial observation of neurons exposed to glutamate in Ca-free solution showed that the resultant acute perikaryal swelling was short-lived; within the next hour the majority of these neurons recovered normal appearance and survived. Such neurons remained morphologically stable for at least several days and did not stain when challenged with trypan blue dye; furthermore, as previously reported (Choi, 1985), electrophysiologic study of these neuronal survivors demonstrated normal resting potentials ( $58 \pm 7 \mathrm{mV}, \mathrm{SD}, n=15$ ) and normal excitability: 15 of 15 cells exhibited action potentials, and 13 of 15 cells exhibited spontaneous synaptic activity.

Recent reports have indicated that replacement of extracellular Cl with an impermeant anion blocks GNT in hippocampal cultures (Rothman, 1985) and chick retina (Price et al., 1985). Replacement of $\mathrm{Cl}$ with isothionate similarly attenuated the acute swelling and, to a lesser extent, the late cell death following exposure of cortical neurons to glutamate (Fig. $4 A ; 5$ experiments). This protective effect of isothionate substitution against late cell death was somewhat variable (mean loss of identified neurons in cell counts, $56.2 \pm 10.3 \%, \mathrm{SEM}, n=7$ ) and could be overcome by simultaneously increasing the extracellular $\mathrm{Ca}$ concentration by adding 5-10 $\mathrm{mM} \mathrm{Ca}$ acetate (Fig. $4 B$; mean 

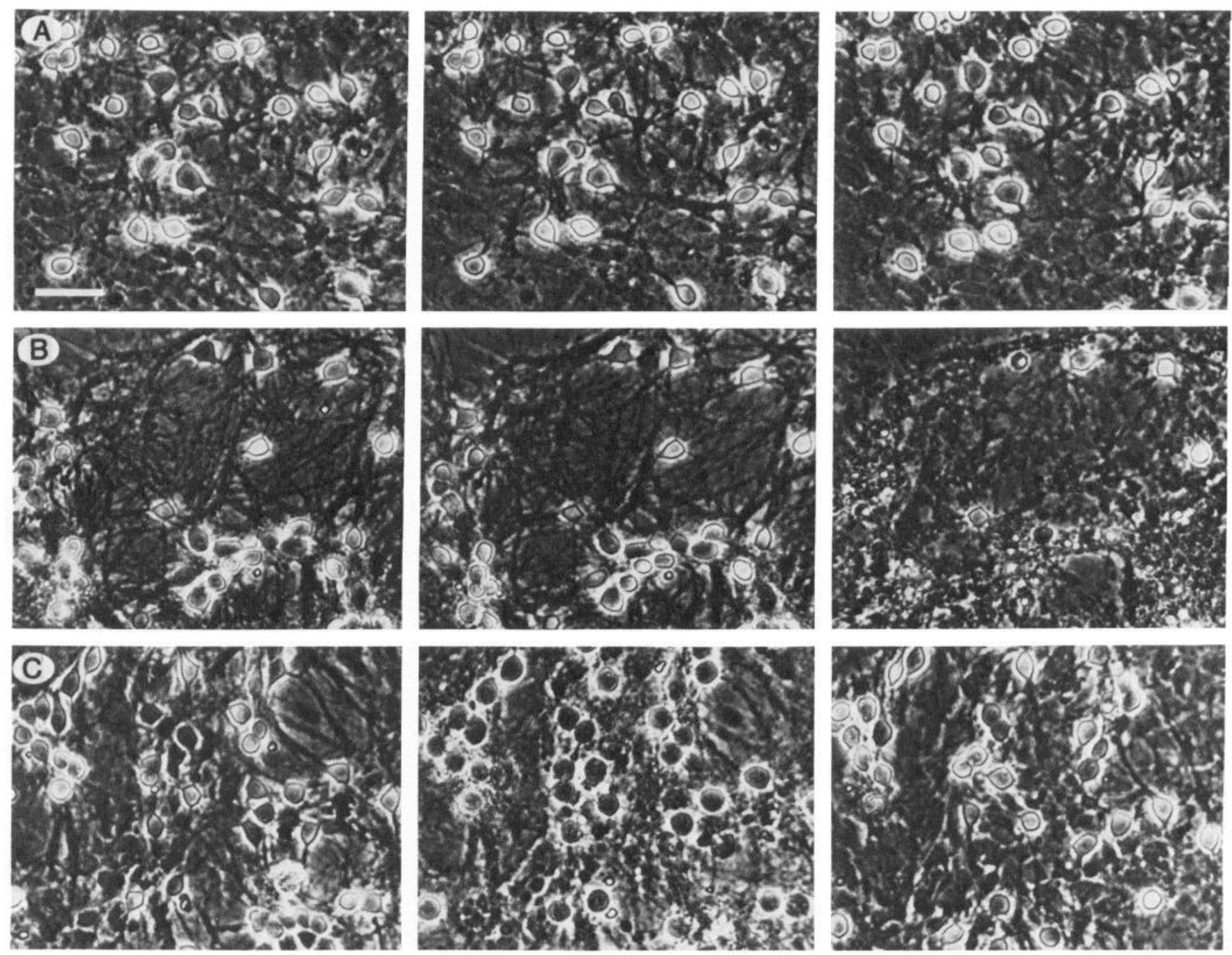

Figure 4. Effects of replacing $\mathrm{Cl}$ on GNT and of high $\mathrm{K}$ alone. Phase-contrast photomicrographs of identified fields of cortical neurons taken before (left column), immediately after (middle column), and $1 \mathrm{~d}$ after (right column) the following toxic exposures by row: $A$, 0.5 mM glutamate for $5 \mathrm{~min}$, chloride-free solution; $B$, same as $A$ (sister culture) but $10 \mathrm{mM}$ Ca acetate added to the chloride-free solution; and $C$, $100 \mathrm{~mm} \mathrm{~K}$ (no glutamate) for $5 \mathrm{~min}$. Bar, $50 \mu \mathrm{m}$.

neuronal loss increased to $88.3 \pm 6.2 \%$, SEM, $n=7$ ). Even with elevated $\mathrm{Ca}$ concentrations, no acute neuronal swelling was seen (Fig. 4B).

Both maneuvers capable of blocking the acute neuronal swelling produced by glutamate exposure, choline substitution and isothionate substitution, would be expected to reduce the influx of $\mathrm{NaCl}$ and water that would follow the opening of membrane glutamate channels permeable to $\mathrm{Na}$. It seemed plausible, therefore, that this acute swelling was a visible concomitant of this "excitotoxic" $\mathrm{NaCl} /$ water influx. To test this possibility, the effect of brief exposure to $100 \mathrm{~mm} \mathrm{~K}$ (without glutamate) was determined (100 mм K solution). Exposure to high $\mathrm{K}$ levels would be expected to produce massive neuronal depolarization with an associated influx of $\mathrm{Cl}$, cations, and water. Widespread acute neuronal swelling, similar to that seen with glutamate, resulted (Fig. $4 C$ ); late cell death was variable (6 experiments).

While the acute neuronal swelling produced by glutamate was blocked by Na replacement, it was not blocked by the addition of $1 \mu \mathrm{M}$ TTX, suggesting that $\mathrm{Na}$ influx through voltage-dependent $\mathrm{Na}$ channels is not required to produce the swelling. Neu- ronal cell loss the next day was also not blocked by TTX (Figs. $3,6 C ; 3$ experiments).

\section{The late, Ca-dependent component of GNT}

Serial observation of identified fields revealed that the neuronal disintegration seen after glutamate exposure in $\mathrm{Na}$-free solution was quite gradual (Fig. 5). While granularity of some neuronal cell bodies and irregularity of processes was apparent within 1 hr of glutamate exposure, other neurons appeared normal within the first few hours only to degenerate over the next several hours.

The observation that GNT could be attenuated by lowering the $1.8 \mathrm{~mm}$ Ca present in the standard exposure salt solution (CSS) led to investigation of the effect of raising extracellular $\mathrm{Ca}$ on GNT. Raising the Ca concentration from 1.8 to $6.8 \mathrm{~mm}$ (by adding $5 \mathrm{mM} \mathrm{CaCl}_{2}$ to CSS) augmented the partial cell loss produced by low concentrations of glutamate (Figs. 3; 6, $A$ and $B)$.

A plausible explanation for the dependence of GNT on extracellular $\mathrm{Ca}$ is that glutamate produces a $\mathrm{Ca}$ influx that triggers lethal intracellular events. Supporting the idea that a $\mathrm{Ca}$ influx 

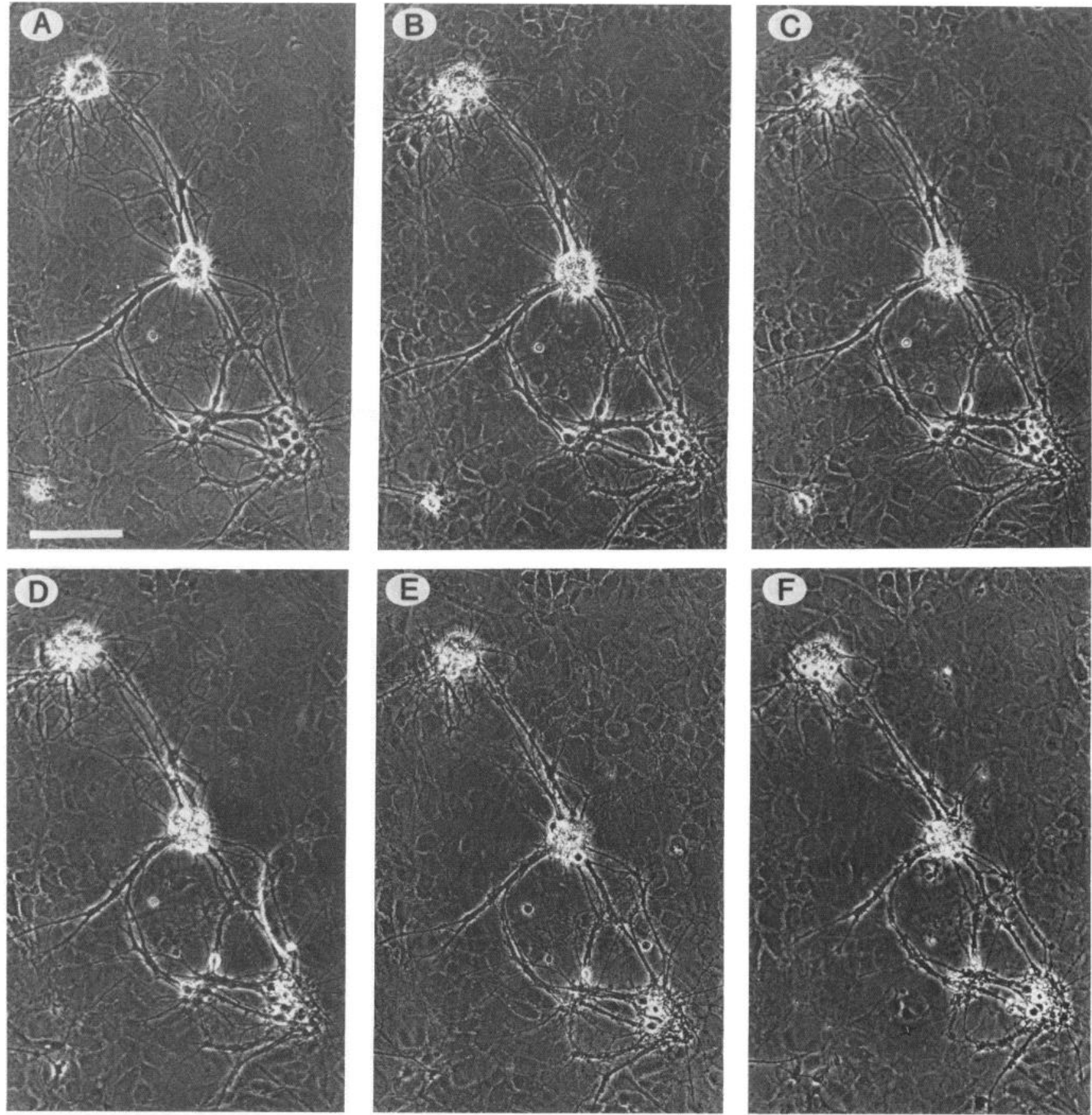

Figure 5. Time course of the late component of GNT. Serial phase-contrast photomicrographs of an identified field of cortical neurons taken before $(A), 1 \mathrm{hr}$ after $(B), 2 \mathrm{hr}$ after $(C), 4 \mathrm{hr}$ after $(D), 9 \mathrm{hr}$ after $(E)$, and $24 \mathrm{hr}$ after $(F)$ exposure to $0.5 \mathrm{~mm}$ glutamate for $5 \mathrm{~min}$ in Na-free solution. Bar, $100 \mu \mathrm{m}$.

per se could mediate subsequent cell damage, incubation of cortical cultures for $15 \mathrm{~min}$ in $20-30 \mu \mathrm{M}$ concentrations of the calcium ionophore A23187 in CSS was found not to produce acute neuronal swelling but did lead to substantial late neuronal death (Fig. 7A; mean neuronal loss in cell counts, $46.3 \pm 15.9 \%$, SEM; $n=5$ ); furthermore, the toxicity of A23187 was enhanced somewhat by increasing the extracellular $\mathrm{Ca}$ concentration during incubation (Fig. 7B; mean neuronal loss increased to $69.0 \pm$ $9.2 \%$, SEM; $n=5$ ). At higher concentrations of A23187 (70$80 \mu \mathrm{M}), 100 \%$ glial as well as $100 \%$ neuronal cell death occurred even in normal (1.8 mM) Ca: The surface of the culture dish was bare by the next day. Control experiments showed that exposure to the DMSO vehicle alone was not toxic to cortical cells.

Because $\mathrm{Mg}$ is known to block voltage-dependent $\mathrm{Ca}$ channels in excitable membranes (Hagiwara and Byerly, 1981), one might predict from the preceding data that high $\mathrm{Mg}$ concentrations should protect against GNT. In fact, in 7 experiments, GNT was only slightly reduced by the addition of $20 \mathrm{mM} \mathrm{MgCl}_{2}$ to CSS (Figs. 3; 8, $A$ and $B$ ). However, in Na-free solution, a large protective effect of $20 \mathrm{mM} \mathrm{MgCl}$, was detected (Figs. 3; 8, C and $D ; 5$ experiments), suggesting that $\mathrm{Mg}$ was capable of fully 

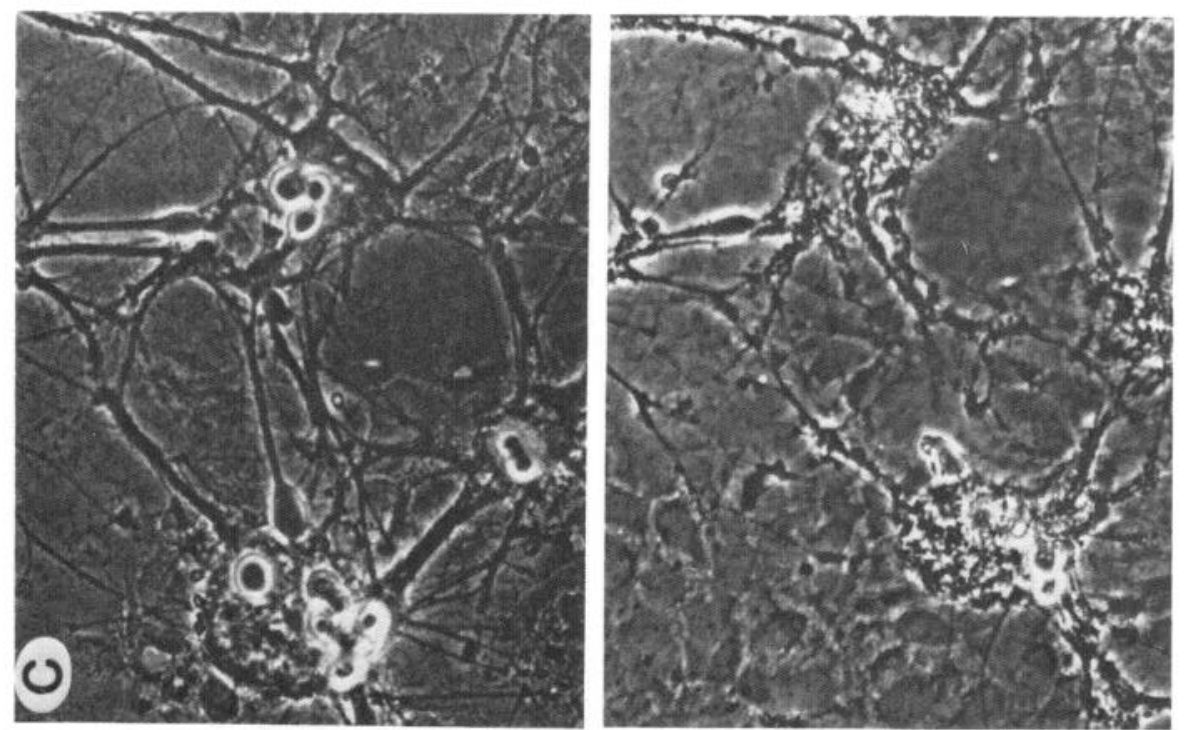

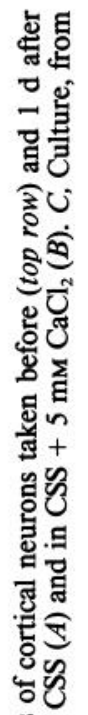
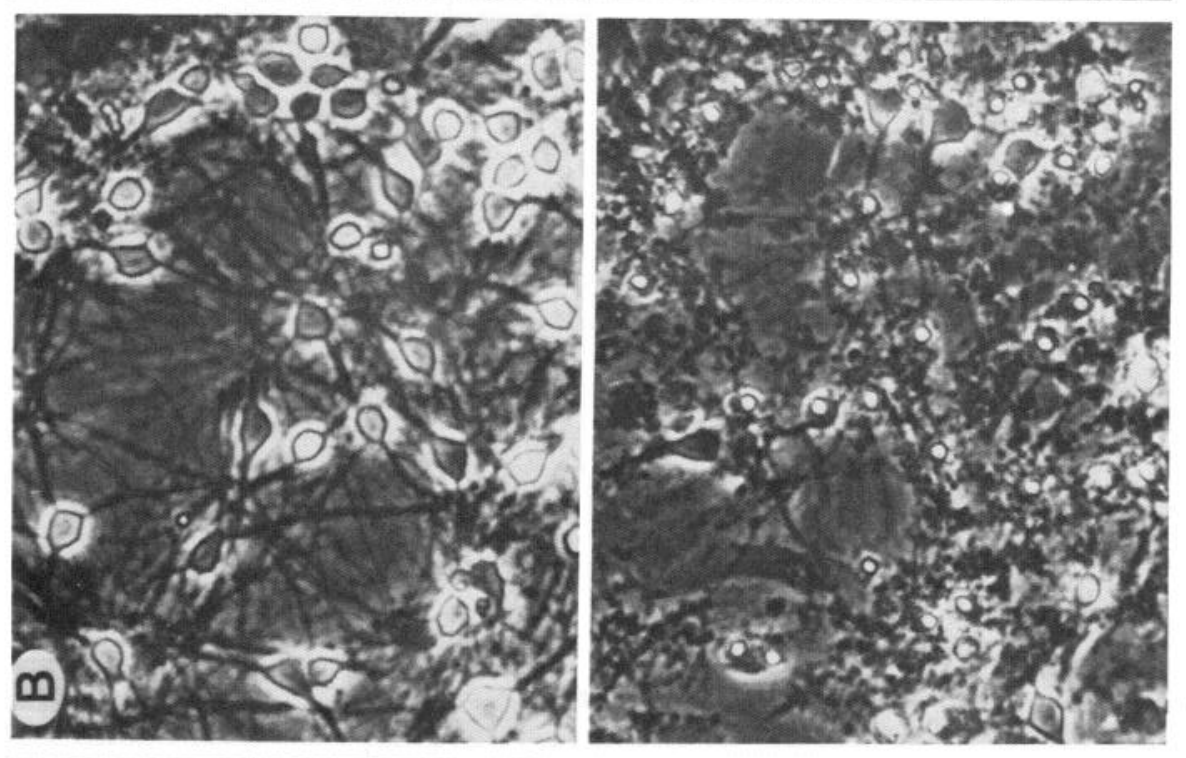

․․․․․․․

莽

\section{品}

远

융

ํㅕㅇ

近骂

음

․․․

\section{음}

ส

옹

苞

ธิํㅇ응

.

可高解

它㲾

उ象
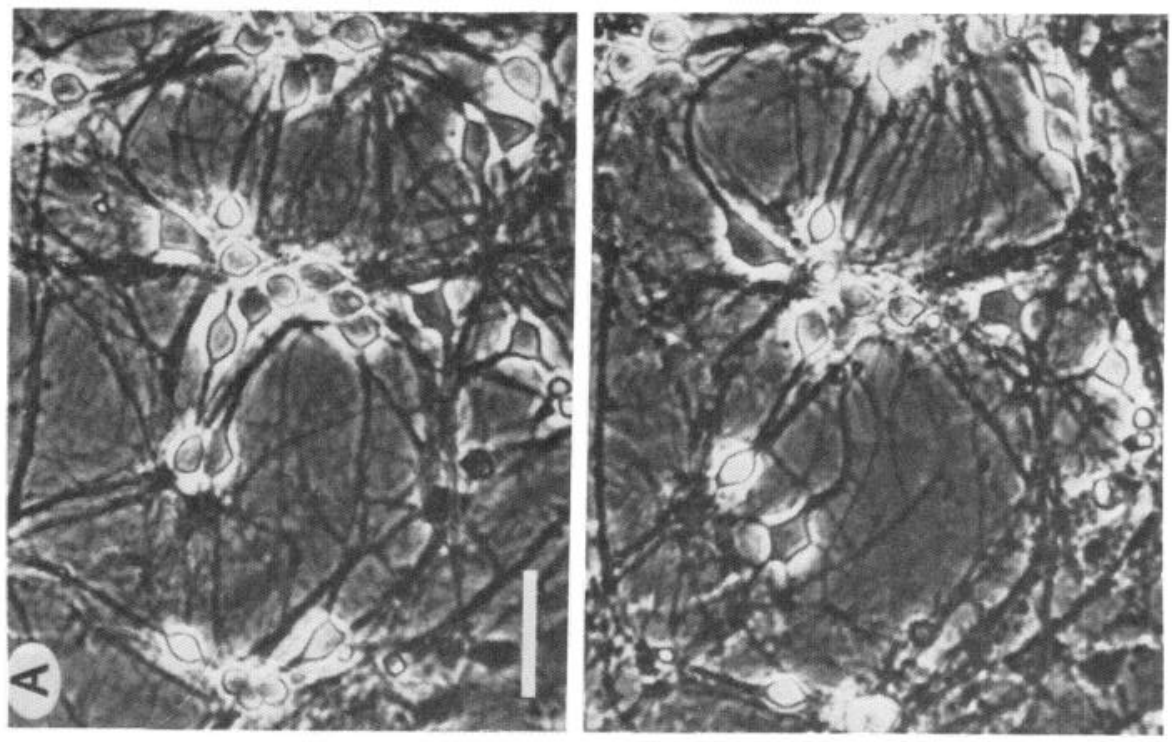

$x-$

F鸟

क्ष

जิ

范

词

동

ơ

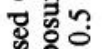

땅응

.

흥

능

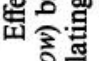

을

\% 호

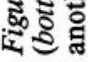



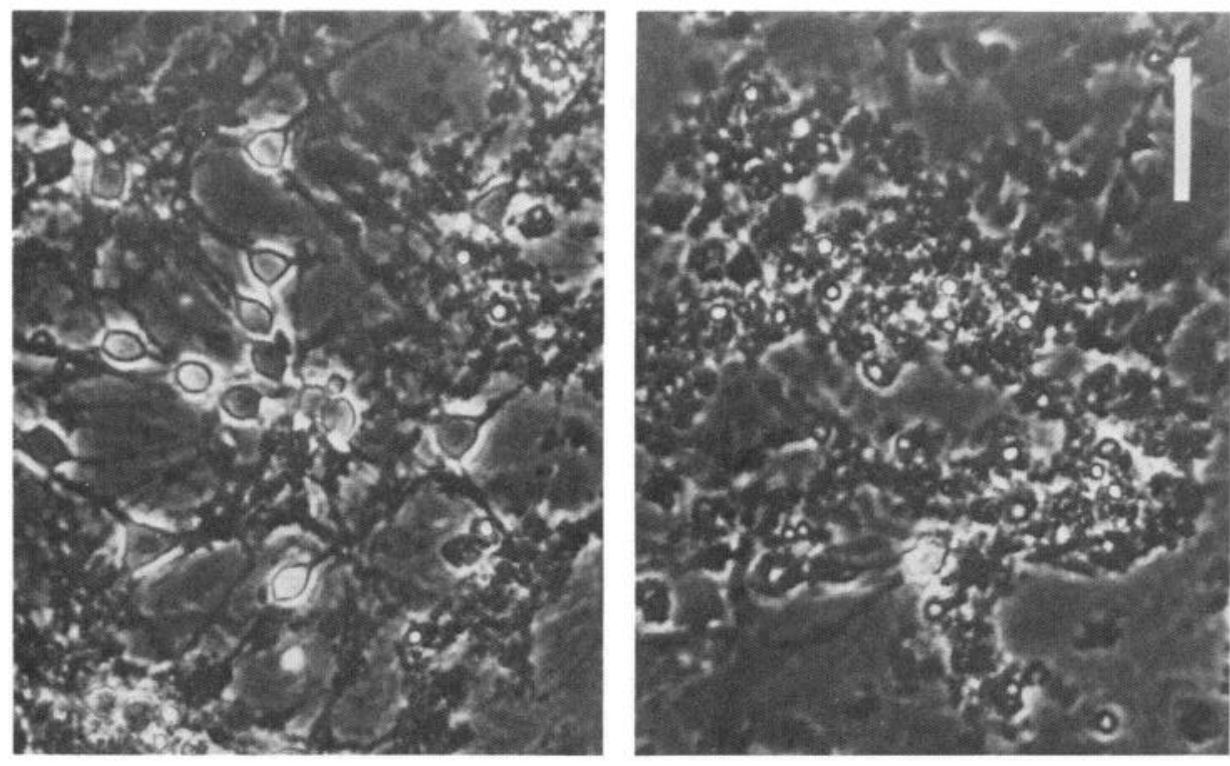

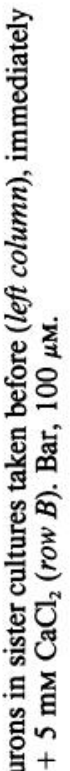
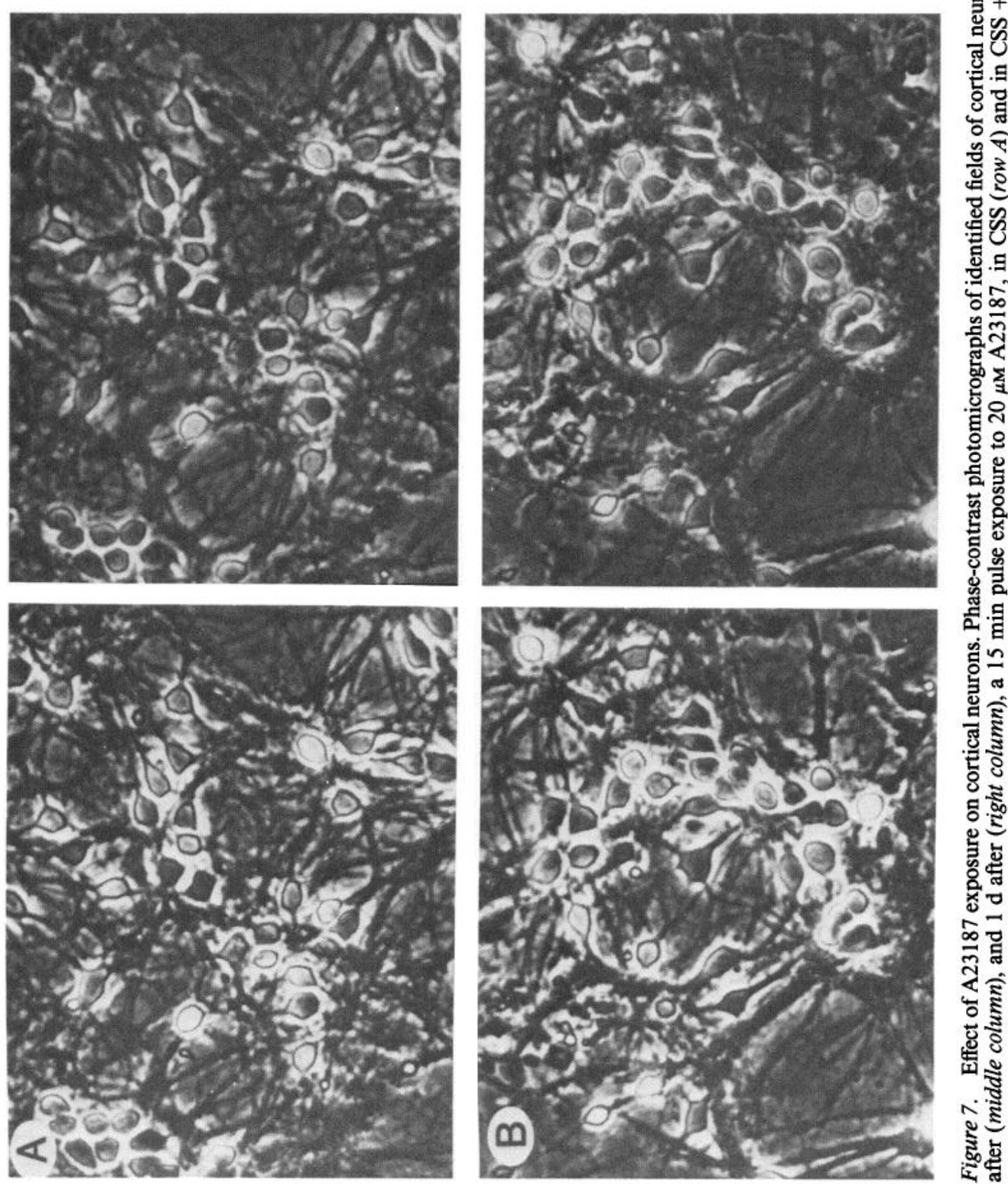

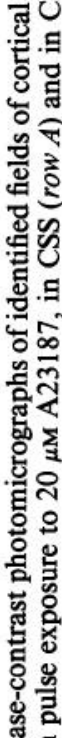

․ㅗㅁ

突的

西

这

తึ

응

8

ร.

늘

氖

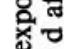

क

䨌

ญิ

논

造

‥

究 
The Journal of Neuroscience, February 1987, 7(2) 377
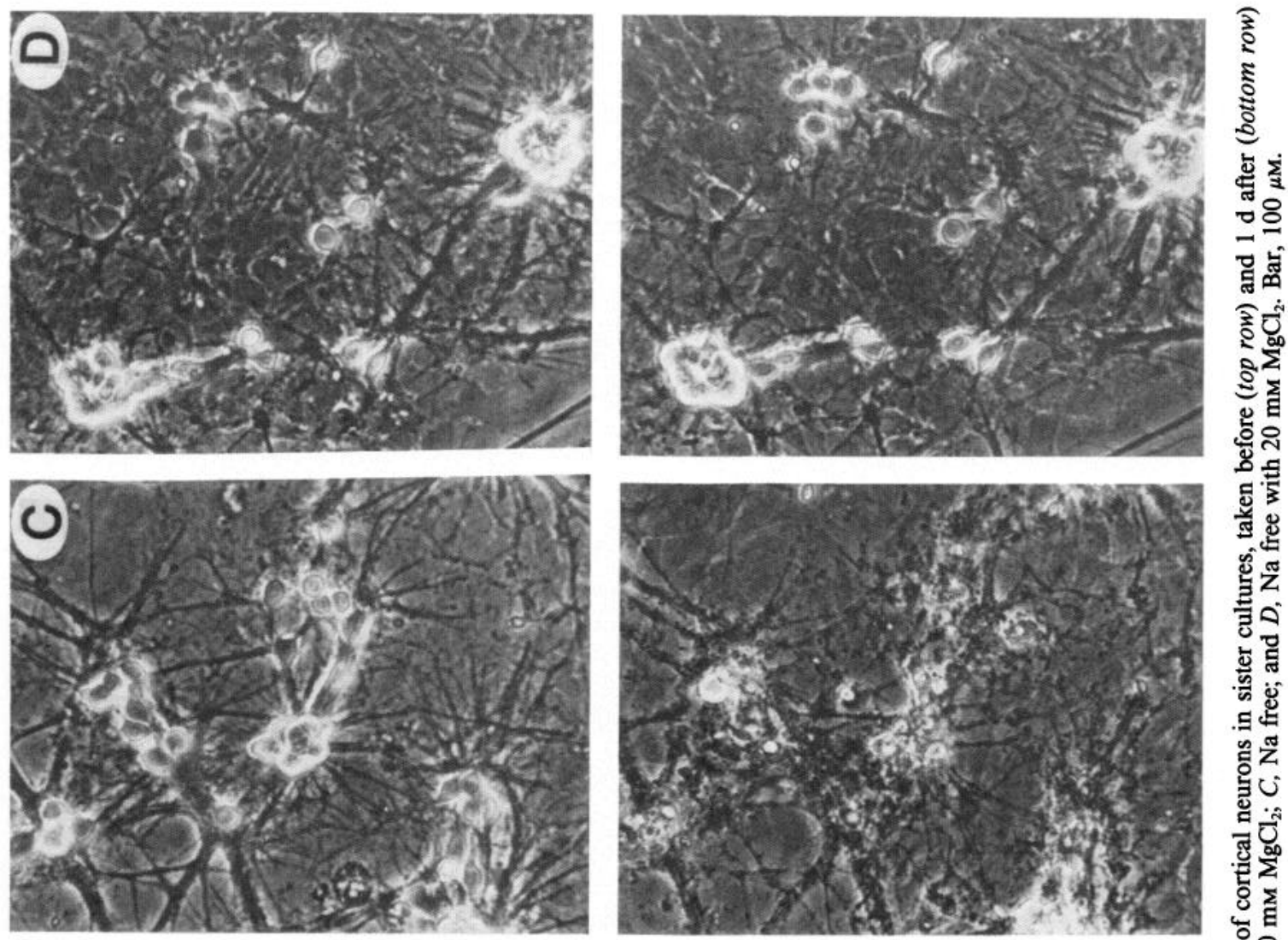

政

芯

氙

를

這

空

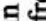

量艺

然

ปั้

త్ెㄹ

등
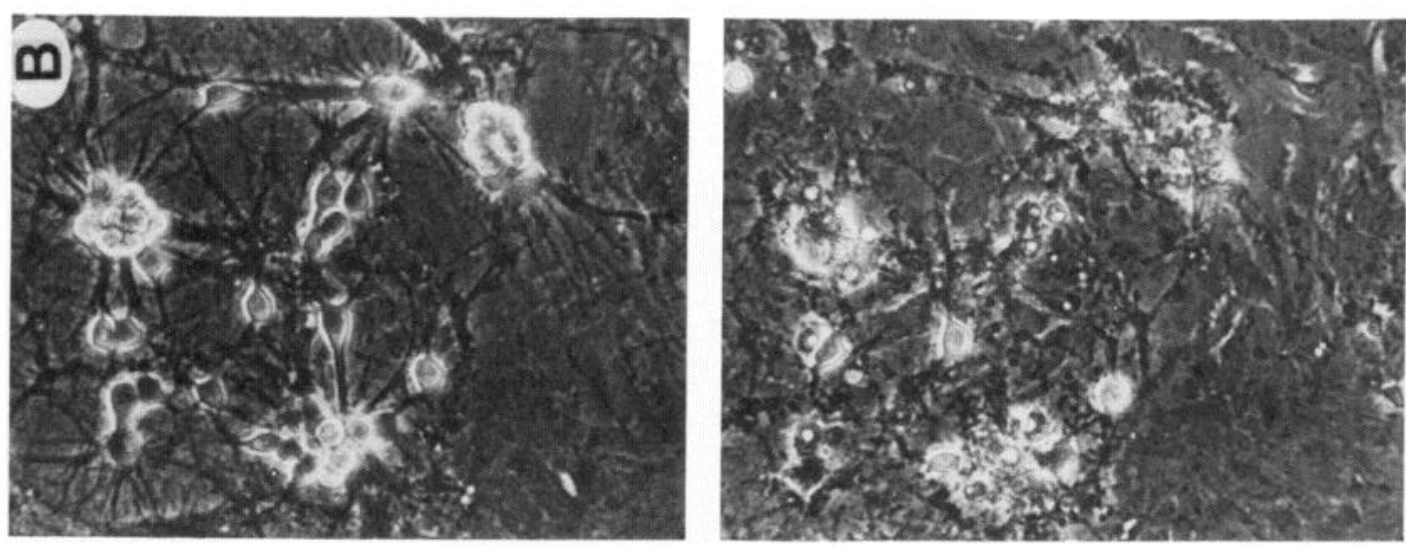

오

西+

8.

正

해

के

証.

웅

光

证

돔

矛

党
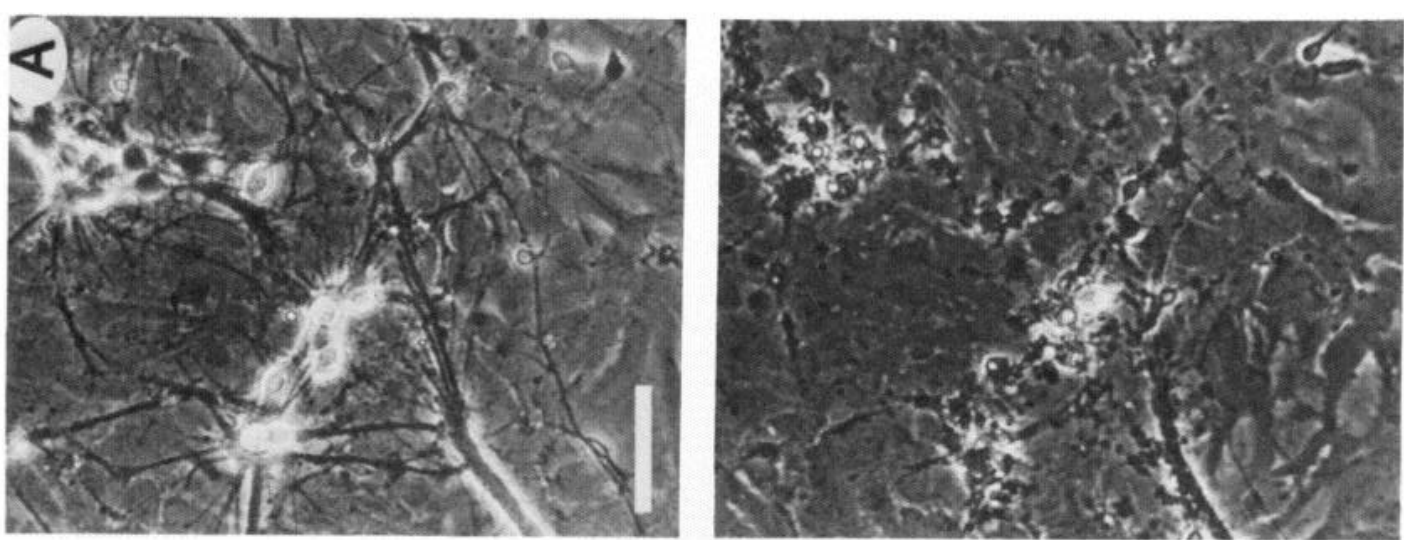

웡응

路

H.

Zัญ

들

号芯

4

흥

路尔

$\infty$

ธิ

Бํㅇ 
antagonizing the effect of $\mathrm{Ca}$ on GNT in the absence of $\mathrm{Na}$.

\section{Discussion}

The present experiments suggest that the neurotoxicity of glutamate on cortical neurons involves 2 components that can be distinguished on the basis of differences in time course and in ionic dependence. The first component, marked by neuronal swelling, occurs actuely, is dependent on extracellular $\mathrm{Na}$ and $\mathrm{Cl}$, can be mimicked by high $\mathrm{K}$, and is thus possibly "excitotoxic." A primary effect of glutamate to open membrane $\mathrm{Na}$ conductances could lead to a large influx of $\mathrm{Na}$, resulting in membrane depolarization and a secondary influx of $\mathrm{Cl}$ and water. The acute morphological swelling seen after glutamate could reflect the volume increase associated with this sequence of events. One explanation for the augmented neuronal swelling seen acutely after glutamate exposure in Ca-free solution would then be a change in the physical properties of the cell membrane (increased compliance), due to lack of the stabilizing influence of $\mathrm{Ca}$ on the membrane (a phenomenon well known to electrophysiologists, who often choose to record in solutions with increased $\mathrm{Ca}$ ). Modest degrees of such excitotoxicity might be reversible, but if carried to an extreme point, irreversible changes and/or cell lysis would be expected to occur.

While some contribution to $\mathrm{Na}$ influx might occur through voltage-dependent Na channels, the lack of effect of TTX on acute swelling suggests that the magnitude of the contribution of voltage-dependent $\mathrm{Na}$ channels to the acute component of GNT is small relative to the contribution of glutamate-activated $\mathrm{Na}$ channels.

The second component, marked by gradual neuronal disintegration, occurs late, is dependent on extracellular $\mathrm{Ca}$, can be mimicked by $A 23187$, and is thus possibly mediated by a transmembrane influx of $\mathrm{Ca}$ into neurons. As discussed above, excess $\mathrm{Ca}$ entry appears to injure cells in general, perhaps in part because of activation of neutral proteases and phospholipase A2 (Siesjo and Wieloch, 1985). It is possible that the late, Cadependent component of GNT may be responsible for some of the delayed neuronal death seen in vivo following certain insults, including ischemia (Plum, 1983).

Glutamate exposure could produce a calcium influx both directly, through glutamate-activated membrane channels (Nicoll and Alger, 1981), and indirectly, though voltage-dependent channels activated by membrane depolarization (Hagiwara and Byerly, 1981). Addition of $20 \mathrm{~mm} \mathrm{Mg}$, however, did not substantially block GNT in control solution; this finding, together with the toxicity of glutamate in $\mathrm{Na}$-frec solution, supports the notion that the activation of voltage-dependent $\mathrm{Ca}$ channels may not normally be required for lethal $\mathrm{Ca}$ entry.

The observations described here are consistent with the reports by Rothman (1985) and Price et al. (1985) that GNT can be demonstrated in the absence of extracellular $\mathrm{Ca}$. Those investigators employed somewhat longer (30 min) glutamate exposures than the 5 min exposures generally used here; with such exposures, extracellular $\mathrm{Ca}$ is also not required for lethal GNT in the cortical cell culture system. The present data suggest that the acute excitotoxic component of GNT, like the late Ca-dependent component, can, if intense, act in isolation to produce irreversible neuronal injury. However, the greater protective effect seen after removing $\mathrm{Ca}$, as compared with that of removing $\mathrm{Na}$, with brief glutamate exposure suggests that the Ca-dependent mechanism predominates at lower glutamate exposures.
The replacement of extracellular $\mathrm{Cl}$ with an impermeant anion was found to attenuate GNT, in agreement with the results of Rothman and Price et al. While it is possible that $\mathrm{Cl}$ ions participate specifically in GNT in some yet undefined manner, this effect of $\mathrm{Cl}$ substitution can be parsimoniously explained in terms of secondary alterations in both the acute and the late components defined above. As suggested by Rothman (1985), $\mathrm{Cl}$ ions are probably drawn into cells depolarized by glutamate or high $\mathrm{K}$, and thus, as the necessary anionic partner, permit a considerable net influx of extracellular cations and water to occur, leading to the observed acute "excitotoxic" neuronal swelling. Removal of extracellular $\mathrm{Cl}$ would limit the occurrence of this acute excitotoxic influx, and similarly could attenuate the net entry of $\mathrm{Ca}$ into neurons, thereby producing some attenuation of the late component of GNT. Raising extracellular $\mathrm{Ca}$ could partially restore net $\mathrm{Ca}$ influx and thus restore GNT.

The ability of high $\mathrm{Mg}$ concentrations to block GNT in the absence of $\mathrm{Na}$ is intriguing; it could be accounted for by the ability of $\mathrm{Mg}$ to attenuate $\mathrm{Ca}$ entry through glutamate-activated channels. $\mathrm{Mg}$ is known to be particularly effective in producing a voltage-dependent blockade of the ion channels linked to the $N$-methyl-D-aspartate (NMDA) subclass of glutamate receptors (Nowak et al., 1984; Mayer and Westbrook, 1985), and in the absence of $\mathrm{Na}$, the ability of glutamate to relieve this block through membrane depolarization (mediated through nonNMDA channels) would likely be limited. The hypothesis that NMDA channels may play a central role in mediating GNT is supported by 2 other recent lines of experiments: First, the selective NMDA antagonist 2-amino-7-phosphonoheptanoic acid has been shown to attenuate the brain damage produced by ischemia (Simon et al., 1984a, b) and hypoglycemia (Wieloch, 1985) in vivo, suggesting that the NMDA receptor may be critically involved in the pathophysiology of neuronal injury in certain disease states. Second, recent voltage-clamp studies of spinal cord neurons filled with the $\mathrm{Ca}$ indicator dye arsenazo III (MacDermott et al., 1986) have found evidence that NMDA, much more than kainate, evokes an increase in membrane $\mathrm{Ca}$ conductance.

Furthermore, in preliminary studies in this laboratory, we found that GNT is mimicked (including dependence on extracellular $\mathrm{Ca}$ ) by brief exposure to $0.5 \mathrm{~mm}$ NMDA and is blocked by $0.5-1 \mathrm{~mm}$ concentrations of the selective NMDA antagonist 2-amino-5-phosphonovalerate (APV) (Davies et al., 1981), amounts of APV that do not eliminate the neuroexcitatory action of glutamate on cortical neurons (Choi et al., 1986). Since glutamate is a mixed agonist acting at both NMDA and nonNMDA (kainate and/or quisqualate) type receptors (Davies et al., 1982), the ability of a selective antagonist such as APV to block GNT is somewhat surprising but might be explained if NMDA channels on cortical neurons mediate the majority of the Ca current evoked by glutamate exposure. Additional studies are warranted to explore the pharmacology of GNT and the possibility of a link between NMDA receptor activation and lethal $\mathrm{Ca}$ influx. Drugs capable of attenuating the $\mathrm{Ca}$ influx associated with glutamate exposure could potentially provide important new approaches to the treatment of a variety of acute and chronic neurological diseases.

\section{References}

Barker, J. L., and R. A. Nicoll (1973) The pharmacology and ionic dependency of amino acid responses in the frog spinal cord. J. Physiol. 228: 259-277. 
Berdichevsky, E., N. Riveros, S. Sanchez-Armass, and F. Orrego (1983) Kainate, N-methylaspartate and othcr cxcitatory amino acids increase calcium influx into rat brain cortex cells in vitro. Neurosci. Lett. 36: 75-80.

Choi, D. W. (1985) Glutamate neurotoxicity in cortical cell culture is calcium dependent. Neurosci. Lett. 58: 293-297.

Choi, D. W., S. Peters, and M. Yokoyama (1986) Glutamate neurotoxicity in cortical cell culture is attenuated by N-methyl-D-aspartate receptor antagonists. Soc. Neurosci. Abstr. 12:381.

Coyle, J. T. (1983) Neurotoxic action of kainic acid. J. Neurochem. 41: $1-11$.

Coyle, J. T., S. J. Bird, R. H. Evans, R. L. Gulley, J. V. Nadler, W. J. Nicklas, and J. W. Olney (1981) Excitatory amino acid neurotoxins: Selectivity, specificity, and mechanisms of action. Neurosci. Res. Prog. Bull. 19: 331-427.

Davies, J., A. A. Francis, A. W. Joncs, and J. C. Watkins (1981) 2-Amino-5-phosphonovalerate (2APV), a potent and selective antagonist of amino acid-induced and synaptic excitation. Neurosci. Lett. 21: 77-81.

Davies, J., R. H. Evan, A. W. Jones, D. A. S. Smith, and J. C. Watkins (1982) Differential activation and blockade of excitatory amino acid receptors in the mammalian and amphibian central nervous systems. Comp. Biochem. Physiol. 72C: 211-234.

Duce, I. R., P. L. Donaldson, and P. N. R. Usherwood (1983) Investigations into the mechanism of excitant amino acid cytotoxicity using a well-characterized glutamatergic system. Brain Res. 263: 77-87.

Hablitz, J. J., and I. A. Langmoen (1982) Excitation of hippocampal pyramidal cells by glutamate in the guinea pig and rat. J. Physiol. (Lond.) 325: 317-331.

Hagiwara, S., and L. Bycrly (1981) Calcium channel. Annu. Rev. Neurosci. 4: 69-125.

Leonard, J. P., and M. M. Salpeter (1979) Agonist-induced myopathy at the neuromuscular junction is mediated by calcium. J. Cell. Biol. 82: 811-819.

Lucas, D. R., and J. P. Newhouse (1957) The toxic effect of sodium L-glutamate on the inner layers of the retina. Arch. Ophthalmol. 58: 193-201.

MacDermott, A. B., M. L. Mayer, G. L. Westbrook, S. J. Smith, and
J. L. Barker (1986) Optical measurement of calcium transients triggered by excitatory amino acids in spinal cord neurons under voltage clamp. Biophys. J. 49: 365a.

Mayer, M. L., and G. L. Westbrook (1985) The action of N-methylD-aspartic acid on mouse spinal neurones in culture. J. Physiol. (Lond.) 361: 65-90.

Nicoll, R. A., and B. E. Alger (1981) Synaptic excitation may activate a calcium-dependent potassium conductance in hippocampal pyramidal cells. Science. 212: 957-959.

Nowak, L., P. Bregestovski, P. Ascher, A. Herbet, and A. Prochiantz (1984) Magnesium gates glutamate-activated channels in mouse central neurones. Nature 307: 462-465.

Olney, J. W., O. L. Ho, and V. Rhee (1971) Cytotoxic effects of acidic and sulphur containing amino acids on the infant mouse central nervous system. Exp. Brain Res. 14: 61-76.

Olney, J. W., V. Rhee, and O. L. Ho (1974) Kainic acid: A powerful neurotoxic analogue of glutamate. Brain Res. 77: 507-512.

Plum, F. (1983) What causes infarction in ischemic brain?: The Robert Wartenberg Lecture. Neurology 33: 222-233.

Price, M. T., J. W. Olney, L. Samson, and J. Labruyere (1985) Calcium influx accompanies but does not cause excitotoxin-induced neuronal necrosis in retina. Brain. Res. Bull. 14: 369-376.

Rothman, S. M. (1985) The neurotoxicity of excitatory amino acids is produced by passive chloride influx. J. Neurosci. 5: 1483-1489.

Schanne, F. A. X., A. B. Kane, E. E. Young, and J. L. Farber (1979) Calcium dependence of toxic cell death: A final common pathway. Science 206: 700-702.

Siesjo, B. K., and T. Wieloch (1985) Cerebral metabolism in ischaemia: Neurochemical basis for therapy. Br. J. Anaesth. 47: 47-62.

Simon, R. P., T. Griffiths, M. C. Evans, J. H. Swan, and B. S. Meldrum (1984a) Calcium overload in selectively vulnerable neurons of the hippocampus during and after ischemia: An electron microscopy study in the rat. J. Cereb. Blood. Flow. Metab. 4: 350-361.

Simon, R. P., J. H. Swan, T. Griffiths, and B. S. Meldrum (1984b) Blockade of N-methyl-D-aspartate receptors may protect against ischemic damage in the brain. Science 226: 850-852.

Wieloch, T. (1985) Hypoglycemia-induced neuronal damage prevented by an $N$-methyl-D-aspartate antagonist. Science 230:681-683. 